\title{
The protective role of Deferoxamine in the
} prevention of hepatic fibrosis in children treated with Doxorubicin: a randomized controlled clinical trial

\section{Mohammadreza Bordbar}

Hematology Research center, shiraz university of medical sciences

Gholamreza Fathpour

Hematology Research Center, Shiraz University of Medical Sciences

\section{Seyed Mohsen Dehghani}

Gastroenterology Research Center, Shiraz University Of Medical sciences,

\section{Sezaneh Haghpanah}

Shiraz University of Medical Sciences

Hossein Molavi Vardanjani

Shiraz University of Medical Sciences

\section{Mohammadreza Fattahi}

Shiraz University of Medical Sciences

\section{Mahdi Shahriari}

Shiraz University of Medical Sciences

Nader Shakibazad ( $\nabla$ nshakibazad@gmail.com )

Bushehr University of Medical Sciences https://orcid.org/0000-0002-5124-6380

Research article

Keywords: Cancer, Deferoxamine, Doxorubicin, Hepatic fibrosis, Pediatrics

Posted Date: March 16th, 2020

DOI: https://doi.org/10.21203/rs.3.rs-17341/v1

License: (a) This work is licensed under a Creative Commons Attribution 4.0 International License. Read Full License 


\section{Abstract}

Background: Hepatic fibrosis is an ominous sign which may follow treatment with Doxorubicin (DOX) chemotherapy. The aim of this study was investigating the protective effect of Deferoxamine (DFO) against hepatic fibrosis in treatment-naïve pediatric cancer patients.

Methods: In this prospective randomized controlled trial, 61 treatment-naïve children (2-18 years) with different types of cancer who referred to a tertiary teaching hospital in South of Iran were enrolled. They were randomly assigned to 3 groups; group 1 (control, $n=21$ ), group 2 (DFO 10 times DOX dose, $n=20$ ), group 3 (DFO $50 \mathrm{mg} / \mathrm{kg}, \mathrm{n}=20$ ). DFO was administered as an 8-hour continuous intravenous infusion during and after DOX infusion in each chemotherapy cycle. Non-invasive serum markers of liver fibrosis including APRI, FIB-4 score and Fibro Test were measured in each individual. Besides, hepatic Fibro Scan was used after the last course of chemotherapy to estimate fibrosis degree.

Results: Fifty-six patients were analyzed. Alanine aminotransferase was mildly increased in the treatment groups compared to pre-treatment. Treatment with DFO 10 times DOX dose was associated with significant decline in post-treatment APRI (adjusted odds ratio $0.17 ; 95 \%$ confidence interval 0.03 0.84). METAVIR fibro scores were in the F0-F1 zone in all participants, and the results were comparable in the study groups. No adverse drug effect was reported in the treatment groups.

Conclusion: DOX may not lead to severe liver fibrosis if the maximum allowed cumulative dose is not exceeded. DFO at the dose of 10 times of DOX dose may have a potential protective role against liver fibrosis. Larger multi-center studies with longer follow up are warranted to further assess this issue.

\section{Introduction}

Anthracyclines are a group of chemotherapy agents which play a main role in the treatment of different types of childhood cancer [1, 2]. They include doxorubicin (DOX), daunorubicin, epirubicin, idarubicin, and mitoxantrone. It is speculated that their anti-neoplastic action is taken through the induction of topoisomerase II, failure of DNA stands and interference with DNA formation. Chemotherapy is generally associated with toxicity to healthy organs including liver[3]. Hepatic damage is usually observed 1 to 4 weeks after the treatment has begun. Hepatotoxicity is often induced by the drugs as hapten and prohapten which lead to immunological injury $[4,5]$. Although the exact mechanism of acute DOX toxicity has yet to be known, it is believed that it is mediated through free radical formation, iron-dependent oxidative damage of biological macromolecules, and lipid peroxidation of cell membrane [6]. Induction of apoptosis and alteration of nitric oxide metabolism are other mechanisms that may be associated with DOX side effects $[7,8]$. The toxicity to vital organs including heart and liver is a major limiting step in wide-spread use of DOX, and a big concern in those who received high cumulative doses of the drug [9].

On the other hand, Deferoxamine (DFO), as an iron chelator, can bind to ferric ion with its hydroxamic acid group, and enhances the drug excretion in the urine. Chelation of excess iron prevents its deposition and damage to several organs and tissues including liver [10]. It also prevents collagen accumulation and 
hepatic satellite cell activity, thus decreases liver injury [11]. In addition, DFO was shown to have antiproliferative effect which may ultimately lead to cell cycle arrest and apoptosis [12]. Furthermore, DFO maintains the activity of the liver enzyme glucose-6-phosphatase [13]. It can also serve as an antioxidant, and reduces liver fibrosis which is manifested as a decreasing trend in serum markers of liver fibrosis including liver hydroxyproline and liver -smooth muscle actin (a-SMA).Therefore, DFO through different mechanisms decreases profibrogenic factors, and inhibits inflammatory cascade [9-12].

There is no single antidote with proven efficacy in the human being to protect against DOX-induced hepatotoxicity. Although a number of animal studies have shown some benefit with using DFO, no clinical trial has been conducted in patients with cancer to assess its efficacy. Therefore, this study was designed to assess whether DFO has any beneficial role in the prevention of hepatotoxicity in children treated with DOX. Our primary endpoint was to compare hepatic fibrosis measurements in treated and non-treated groups. Our secondary endpoint was to assess whether different doses of DFO has different efficacy compared to the control subjects.

\section{Methods}

This single-center, prospective, parallel-group, and randomized-controlled trial was conducted in a referral oncology hospital in south of Iran from July 2016 to April 2017. The study population included treatmentnaïve children with the age range of 2-18 years with different types of cancer who were going to be treated with DOX as part of their chemotherapy regimen. Patients with primary or metastatic liver tumors, and those with underlying liver disease or active hepatitis B or C infection were excluded. The study was approved by the Ethics Committee of Shiraz University of Medical Sciences with the code number IR.SUMS.REC.1394.193. The study protocol was registered in Iranian Registry of Clinical Trials at www.irct.ir with registry number IRCT2016080315666N4. Informed written consent was obtained from all participants or their parents.

Given that there was no previous experience with DFO with regards to its hepatoprotective effect in cancer patients, we assumed that patients treated with DFO would have lower probability of DOXassociated liver fibrosis compared to the non-treated patients. Therefore, we used aspartate aminotransferase [AST]-to-Platelet Ratio Index (APRI) as an indirect marker of hepatic fibrosis, and compared APRI in the treatment groups with their control counterparts. A value of 0.5 was considered as the cut-off point to discriminate mild vs no fibrosis [14]. A five percent decrease in the baseline APRI was considered as an acceptable antifibrotic effect [15].

Accordingly, assuming a type I error of 0.05 , and a statistical power of $80 \%$, minimum sample size was estimated at 16 patients in each study group. We decided to enroll at least 20 patients in each group to compensate for a possible $20 \%$ drop out due to lost to follow up.

During the study period, 123 new cases were admitted in our center that 85 patients were eligible to be enrolled. Among these eligible patients, 61 persons accepted to participate in the study. They were randomly allocated to three groups using a computer-generated block randomization sequence which 
was done by a statistician who was blind to the study protocol. Group $1(n=21)$ consisted of patients who served as control group, and no intervention was done. Patients allocated to group $2(n=20)$ and group $3(n=20)$ were pre-treated with DFO (Desferal ${ }^{\circledR}$, Novartis, Switzerland) 10 times the DOX dose and $50 \mathrm{mg} / \mathrm{kg}$, respectively. Intravenous infusion of DFO was started 2 hours prior to starting chemotherapy, continued during DOX infusion (at least 4 hours), and for another 2 hours after termination of the infusion, making up a total of 8 hours. This regimen was repeated in each chemotherapy course alongside with the infusion of DOX.

Liver function tests (LFT) and complete blood count (CBC) were measured before and after treatment.

After the last course of chemotherapy, $y$-glutamyltransferase ( $\mathrm{YGT}$ ), Haptoglobin, a 2 -macroglobulin ( $\mathrm{a} 2$ MG) and apolipoprotein A1 (apoA1) were measured by Enzyme linked immunosorbent assay (ELISA) (Bioassay, China). FIB-4 score and APRI were calculated using the following formulas: FIB-4 score = [age $(\mathrm{Y}) \times \operatorname{AST}(\mathrm{U} / \mathrm{L})]$ / [platelet count $\left(10^{9} / \mathrm{L}\right) \times$ square root of alanine aminotransferase $\left.(\mathrm{ALT})(\mathrm{U} / \mathrm{L})\right]$.

APRI $=[$ AST $(U / L) / 45] \times 100 /$ platelet $\left(10^{9} / \mathrm{L}\right)$

FIB-4 score $\leq 1.45$ and APRI $\leq 0.5$ were considered as no fibrosis while the values more than 3.25 and 1.5 were regarded as significant fibrosis, respectively $[14,16,17]$. FIB-4 Scores were dichotomized as zero for scores equal or less than 1.45 and one for scores more than 1.45 [18].

FibroTest combines five standard biomarkers including $\mathrm{YGT}$, total bilirubin, a2 MG, apoA1, and Haptoglobin. These markers are weighted depending on the patient's age and sex. A cut-off value of 0.58 was assigned to delineate severe fibrosis [19].

Additionally, liver stiffness was measured in all patients by FibroScan or transient elastography (TE) (Echosens, Paris, France). Liver stiffness was evaluated while the patient was lying on dorsal decubitus position, with the arms in maximal abduction. The measurements were taken in the right and left intercostal spaces. Liver stiffness was expressed in kilopascals $(\mathrm{kPa})$ and was computed for each subject as the median of 10 validated measurements in accordance with the manufacturer's instructions. Measurements with an interquartile range of $<30 \%$ of the median value and a success rate of $>60 \%$ were considered reliable. Two-dimensional shear wave elastography (SWE) studies were performed using the Aixplorer ultrasound system (SuperSonic Imagine SA, Aix-en-Provence, France) with a convex broadband probe (SC6-1, Super-Sonic Imagine). This technique has an advantage that the probe can be installed on ultrasound machines. At the time of SWE examination, the patients were asked to hold their breath for 3 to $4 \mathrm{~s}$. Liver stiffness was recorded in the right lobe, while the patient was lying on dorsal decubitus position, in accordance with the protocol used for FibroScan. An SWE box was placed 1.5 to $2 \mathrm{~cm}$ away from the Glisson capsule and on liver parenchyma to avoid measurements of large vessels. For quantitative measurements, a round region of interest was placed inside the SWE box, and minimum and maximum values of stiffness expressed in $\mathrm{kPa}$ were recorded. Four measurements were made, and the median value was recorded. METAVIR fibrosis score, which is graded on a 5-point scale from 0 to 4 , was 
used to delineate the degree of fibrosis (Supplement Table 1). The scores were compared between the three groups.

Normality of data was checked by Shapiro-Wilk test. Bivariate comparison of quantitative variables among three groups was done by ANOVA and Kruskal Wallis tests. Chi-square test was used to compare qualitative variables between the three groups. Paired t-test, Wilcoxon signed-rank test, and McNemar's test were used to compare data before and after treatment in each group. Null hypothesis was assumed to be a decrease of less than $5 \%$ of APRI scores compared with their respective baselines. Then, a binary variable was generated considering change value in the patient APRI score (i.e. APRI score after the intervention minus APRI score at baseline), in which patients with more than five percent decrease in their APRI score considered as observations with good outcome and others were defined as poor outcome observations. Binary Logistic regression was applied to estimate independent (Adjusted for age, sex and baseline APRI score) effect of the treatment in terms of adjusted odds ratio (OR) and its robust $95 \%$ confidence interval $(95 \% \mathrm{Cl})$. A two-sided $p$-value of less than 0.05 or a one-sided $p$ less than 0.025 were considered statistically significant. Data were analyzed using SPSS software (version 21).

\section{Results}

During the study period, one patient who was assigned to group 2 and 2 patients in group 3 died of cancer. Another 2 patients in group 3 withdrew their consents and were excluded. Therefore, the study ended with 56 patients. No adverse drug reaction was reported with using DFO in the treatment groups. The study flowchart is available in the supplement file (Fig. 1).

The patients in three groups were statistically comparable in terms of age, sex and duration of treatment (Table 1). 
Table 1

Demographic data of the study population

\begin{tabular}{|c|c|c|c|c|}
\hline Variable & Group 1 & Group 2 & Group 3 & P-value \\
\hline $\begin{array}{l}\text { Number } \\
\text { (Male/Female) }\end{array}$ & $21(16 / 5)$ & 19(15/4) & $16(11 / 5)$ & 0.62 \\
\hline $\begin{array}{l}\text { Age }(y) \\
(\text { Mean } \pm \text { SD) }\end{array}$ & $6.8 \pm 4.8$ & $7.9 \pm 4.7$ & $8.6 \pm 4.8$ & 0.7 \\
\hline Body surface area $\left(/ \mathrm{m}^{2}\right)($ Mean $\pm S D)$ & $\begin{array}{l}0.93 \pm \\
0.40\end{array}$ & $\begin{array}{l}0.92 \pm \\
0.35\end{array}$ & $1 \pm 0.33$ & 0.55 \\
\hline $\begin{array}{l}\text { Malignancy (\%) } \\
\text { Leukemia } \\
\text { Lymphoma } \\
\text { Other tumors }\end{array}$ & $\begin{array}{l}11(52.4 \%) \\
7(33.3 \%) \\
3(14.3 \%)\end{array}$ & $\begin{array}{l}9(47.4 \%) \\
8(42.1 \%) \\
2(10.5 \%)\end{array}$ & $\begin{array}{l}8(50 \%) \\
6(37.5 \%) \\
2(12.5 \%)\end{array}$ & 0.57 \\
\hline Duration of treatment(Mo) (Mean \pm SD) & $14 \pm 4$ & $10 \pm 3$ & $12 \pm 4$ & 0.61 \\
\hline $\begin{array}{l}\text { Doxorubicin cumulative dose }\left(\mathrm{mg} / \mathrm{m}^{2}\right) \text { (Mean } \pm \\
\text { SD) }\end{array}$ & $225 \pm 132$ & $224 \pm 116$ & $\begin{array}{l}218 \pm \\
130\end{array}$ & 0.68 \\
\hline
\end{tabular}

Mean parameters of CBC and LFT, pre- and post-treatment with DFO were compared between the 3 groups, and the results were shown in Table 2. 
Table 2

Complete blood count and liver function tests in the study population pre- and post-treatment with Deferoxamine*

\begin{tabular}{|c|c|c|c|c|}
\hline Pre-treatment values & $\begin{array}{l}\text { Group } 1 \\
(n=20)\end{array}$ & $\begin{array}{l}\text { Group } 2 \\
(n=19)\end{array}$ & $\begin{array}{l}\text { Group } 3 \\
(n=16)\end{array}$ & $\begin{array}{l}P_{1} \\
\text { value }\end{array}$ \\
\hline WBC $\left(10^{9} / L\right)$ & $11.15 \pm 15.98$ & $8.09 \pm 7.65$ & $18.47 \pm 23.60$ & 0.17 \\
\hline Hemoglobin (g/dl) & $10.12 \pm 2.71$ & $9.55 \pm 1.34$ & $9.61 \pm 2.61$ & 0.69 \\
\hline Platelet $\left(10^{9} / \mathrm{L}\right)$ & $181.19 \pm 128.28$ & $203.79 \pm 120.39$ & $160.750 \pm 152.78$ & 0.63 \\
\hline Total protein (g/dl) & $\begin{array}{l}6.03(5.12- \\
8.01)\end{array}$ & $5.90(4.25-7.30)$ & $6.10(5.05-8.90)$ & 0.57 \\
\hline Albumin (g/dl) & $4.0(3.10-5.40)$ & $3.90(2.70-5.00)$ & $3.75(3.00-4.50)$ & 0.41 \\
\hline Total bilirubin (mg/dl) & $\begin{array}{l}0.50(0.40- \\
1.50)\end{array}$ & $0.53(0.25-2.20)$ & $0.52(0.23-2.40)$ & 0.53 \\
\hline Direct bilirubin (mg/dl) & $\begin{array}{l}0.10(0.01- \\
0.40)\end{array}$ & $0.10(0.10-0.30)$ & $0.10(0.10-0.90)$ & 0.42 \\
\hline $\begin{array}{l}\text { Aspartate aminotransferase } \\
(\mathrm{U} / \mathrm{dl})\end{array}$ & $\begin{array}{l}33.0(15.0- \\
78.0)\end{array}$ & $31.0(11.0-286.0)$ & $32.50(11.0-73.0)$ & 0.35 \\
\hline $\begin{array}{l}\text { Alanine aminotransferase } \\
(\mathrm{U} / \mathrm{dl})\end{array}$ & $27.0(8.0-136.0)$ & $19.0(11.0-317.0)$ & $20.50(5.0-115.0)$ & 0.47 \\
\hline Alkaline phosphatase (U/dl) & $\begin{array}{l}367.0(230.0- \\
760.0)\end{array}$ & $\begin{array}{l}370.0(210.0- \\
2850.0)\end{array}$ & $\begin{array}{l}335.0(246.0- \\
952.0)\end{array}$ & 0.62 \\
\hline \multicolumn{5}{|l|}{ Post-treatment values } \\
\hline WBC $\left(10^{9} / L\right)$ & $4.48 . \pm 1.44$ & $7.0 \pm 6.78$ & $8.73 \pm 9.15$ & 0.13 \\
\hline$P_{2}$ value & 0.07 & 0.68 & 0.10 & \\
\hline Hemoglobin (g/dl) & $10.23 \pm 1.62$ & $9.84 \pm 0.83$ & $10.11 \pm 1.12$ & 0.60 \\
\hline$P_{2}$ value & 0.82 & 0.40 & 0.44 & \\
\hline Platelet $\left(10^{9} / \mathrm{L}\right)$ & $161.08 \pm 93.93$ & $199.59 \pm 85.08$ & $198.12 \pm 114.66$ & 0.37 \\
\hline $\mathrm{P}_{2}$ value & 0.28 & 0.88 & 0.31 & \\
\hline \multicolumn{5}{|c|}{$\begin{array}{l}\text { Group 1: control group; group 2: treated with Deferoxamine } 10 \text { times the Doxorubicin dose; group 3: } \\
\text { treated with Deferoxamine } 50 \mathrm{mg} / \mathrm{kg}\end{array}$} \\
\hline $\begin{array}{l}\text { *Data related to parameters } w \\
\text { deviation, and those related to } \\
P_{1} \text { is related to the compariso } \\
\text { and post-treatment values in } €\end{array}$ & $\begin{array}{l}\text { h normal distribut } \\
\text { non-normal distrib } \\
\text { of values betweer } \\
\text { ch group. }\end{array}$ & $\begin{array}{l}n \text { are summarized } \\
\text { ion are shown as } n \\
\text { he } 3 \text { groups; } P_{2} \text { is } r\end{array}$ & $\begin{array}{l}\text { mean and standaro } \\
\text { dian and interquarti } \\
\text { ated to the comparis }\end{array}$ & $\begin{array}{l}\text { ange. } \\
\text { of pre- }\end{array}$ \\
\hline
\end{tabular}




\begin{tabular}{|c|c|c|c|c|}
\hline Pre-treatment values & $\begin{array}{l}\text { Group } 1 \\
(n=20)\end{array}$ & $\begin{array}{l}\text { Group } 2 \\
(n=19)\end{array}$ & $\begin{array}{l}\text { Group } 3 \\
(n=16)\end{array}$ & $\begin{array}{l}P_{1} \\
\text { value }\end{array}$ \\
\hline Total protein (g/dl) & $6.0(5.0-7.45)$ & $5.80(4.25-6.45)$ & $5.87(4.75-7.0)$ & 0.52 \\
\hline$P_{2}$ value & 0.20 & 0.10 & 0.046 & \\
\hline Albumin (g/dl) & $\begin{array}{l}3.95(3.05- \\
4.50)\end{array}$ & $3.90(2.90-4.35)$ & $3.85(2.75-4.25)$ & 0.40 \\
\hline$P_{2}$ value & 0.56 & 0.80 & 0.85 & \\
\hline Total bilirubin (mg/dl) & $\begin{array}{l}0.5 .0(0.25- \\
2.20)\end{array}$ & $0.55(0.25-1.50)$ & $0.57(0.30-1.85)$ & 0.35 \\
\hline $\mathrm{P}_{2}$ value & 0.52 & 0.22 & 0.79 & \\
\hline Direct bilirubin (mg/dl) & $\begin{array}{l}0.10(0.05- \\
0.50)\end{array}$ & $0.11(0.01-0.31)$ & $0.15(0.10-0.75)$ & 0.65 \\
\hline $\mathrm{P}_{2}$ value & 0.41 & 0.48 & 1.00 & \\
\hline $\begin{array}{l}\text { Aspartate aminotransferase } \\
(\mathrm{U} / \mathrm{dl})\end{array}$ & $\begin{array}{l}32.50(9.50- \\
84.0)\end{array}$ & $\begin{array}{l}29.50(18.0- \\
355.50)\end{array}$ & $26.25(16.0-111.0)$ & 0.47 \\
\hline $\mathrm{P}_{2}$ value & 0.09 & 0.43 & 0.34 & \\
\hline $\begin{array}{l}\text { Alanine aminotransferase } \\
(\mathrm{U} / \mathrm{dl})\end{array}$ & $\begin{array}{l}28.50(14.0- \\
106.50)\end{array}$ & $\begin{array}{l}36.0(23.0- \\
698.50)\end{array}$ & $31.50(18.0-225.0)$ & 0.43 \\
\hline $\mathrm{P}_{2}$ value & 0.42 & 0.03 & 0.03 & \\
\hline Alkaline phosphatase (U/dl) & $\begin{array}{l}324.0(215.0- \\
545.0)\end{array}$ & $\begin{array}{l}380.0(171.0- \\
525.0)\end{array}$ & $\begin{array}{l}331.25(221.50- \\
540.0)\end{array}$ & 0.57 \\
\hline$P_{2}$ value & 0.21 & 0.64 & 0.28 & \\
\hline \multicolumn{5}{|c|}{$\begin{array}{l}\text { Group 1: control group; group 2: treated with Deferoxamine } 10 \text { times the Doxorubicin dose; group 3: } \\
\text { treated with Deferoxamine } 50 \mathrm{mg} / \mathrm{kg}\end{array}$} \\
\hline \multicolumn{5}{|c|}{$\begin{array}{l}{ }^{*} \text { Data related to parameters with normal distribution are summarized as mean and standard } \\
\text { deviation, and those related to non-normal distribution are shown as median and interquartile range. } \\
P_{1} \text { is related to the comparison of values between the } 3 \text { groups; } P_{2} \text { is related to the comparison of pre- } \\
\text { and post-treatment values in each group. }\end{array}$} \\
\hline
\end{tabular}

The measured background parameters were initially comparable in the study groups. Similarly, no difference was observed following treatment between the study groups regarding these background characteristics (Table 3). When pre- and post-treatment values of background variables were compared in each group, only total protein in group $3(6 \mathrm{mg} / \mathrm{dl}$ vs $5.87 \mathrm{mg} / \mathrm{dl}, \mathrm{p}=0.047)$ and ALT in group $2(19 \mathrm{mg} / \mathrm{dl}$ vs $36 \mathrm{mg} / \mathrm{dl})$, and group $3(20.5 \mathrm{mg} / \mathrm{dl}$ vs $31.5 \mathrm{mg} / \mathrm{dl})$ were significantly different $(p=0.03)$. 
Table 3

Comparison of indirect serum markers of liver fibrosis in the study groups*

\begin{tabular}{|lllll|}
\hline & $\begin{array}{l}\text { Group 1 } \\
(\mathbf{n = 2 1 )}\end{array}$ & $\begin{array}{l}\text { Group 2 } \\
(\mathbf{n = 1 9 )}\end{array}$ & $\begin{array}{l}\text { Group 3 } \\
(\mathbf{n = 1 6 )}\end{array}$ & P value \\
\hline $\begin{array}{l}\text { APRI } \\
\text { Pre-treatment } \\
\text { Post-treatment }\end{array}$ & $\begin{array}{l}0.62(0.31-1.53) \\
0.66(0.33-0.89)\end{array}$ & $\begin{array}{l}0.52(0.27-1.09) \\
0.43(0.36-0.64)\end{array}$ & $\begin{array}{l}0.57(0.24-3.59) \\
0.38(0.25-0.66)\end{array}$ & 0.87 \\
\hline P $_{2}$ value** & $0.06^{\$}$ & $0.22^{\$}$ & $0.015^{\$}$ & \\
\hline $\begin{array}{l}\text { FIB-4 score\# } \\
\text { Pre-treatment } \\
\text { Post-treatment }\end{array}$ & $0.27(0.09-0.71)$ & $0.27(0.19-0.44)$ & $0.38(0.21-1.68)$ & 0.23 \\
\hline P2 value & $0.17(0.11-0.52)$ & $0.20(0.13-0.34)$ & $0.21(0.11-0.40)$ & 0.99 \\
\hline FibroTest & $0.725^{\$}$ & & & \\
& 0.006 & $0.191^{\$}$ & $0.020^{\$}$ & 0.33 \\
\hline
\end{tabular}

Group 1: control group; group 2: treated with Deferoxamine 10 times the Doxorubicin dose; group 3: treated with Deferoxamine $50 \mathrm{mg} / \mathrm{kg}$;

GT: gamma glutamyl transferase; $\mathrm{a}_{2} \mathrm{MG}$ : alpha2 macroglobulin; APOA1: apolipoprotein A1; APRI: ASTto-platelet ratio index

*Data are shown as median and interquartile range

**Alternative hypothesis: Pre-treatment APRI score -post-treatment APRI score $>0.5^{\star}$ pre-treatment APRI score

\# FIB-4 Scores were dichotomized as zero for scores equal or less than 1.45 and one for scores more than 1.45 .

$\$$ Exact one-sided $\mathrm{p}$-value provided by McNemar's test

Regarding indirect serum biomarkers of liver fibrosis, percentage of at-risk patients according to the FIB-4 score was significantly decreased in group 3 following treatment with DFO (McNemar's test $p=0.02$ ). There was no statistically significance association between group and FIB-4 score after the study period $(p=0.99)$. In terms of change in the APRI score, although treatment in group 3 had a significant antifibrotic effect compared with patients' baseline APRI score (one-sided p value 0.015) (Table 3), no statistically independent effect was observed compared with control group (adjusted OR, 0.327; 95\% Cl: 0.028-3.78). Comparison of odds of an acceptable ant fibrotic effect of treatment in group 2 compared with the control group was at 0.17 with a $95 \% \mathrm{Cl}$ of 0.03 to 0.84 , adjusted for age, sex and patients' baseline APRI score.

The scores were not significantly associated with duration of treatment and DOX cumulative dose of the patients (data not shown). With regards to FibroTest, except one patient in group 3 who exceeded the cutoff value of 0.58 , other patients were within the safe zone of mild or no fibrosis. 
Figure 2 shows the comparison of Fibroscore among the 3 study groups following treatment with DFO. All patients had METAVIR scores in the F0-F1 zones with no significant difference between groups.

\section{Discussion}

This study was the first human clinical trial designed to investigate the protective role of DFO against DOX-induced liver injury in pediatric patients with cancer. We could show that DOX didn't have significant toxicity to the liver tissue at least in the short-term, though transient transaminases were seen in a subgroup of patients. There was no intergroup difference in the LFT parameters of patients treated with DFO and the group. Within each group, all parameters remained comparable except a small rise in ALT level in groups $2 \& 3$ and a minor drop in total protein in group 3, though within the normal range (Table $3)$. Due to lack of similar clinical trials in the past, we couldn't compare our results with them. However, in a few animal studies like Saad's study [20], they reported that DFO with the dosage of 15-20 times of DOX dose may decrease serum AST levels in rat models. This was not observed in our study.

We also checked some indirect serum markers of fibrosis, and found that APRI and FIB-4 score were significantly decreased in patients who were pre-treated with higher dose DFO (group $3,50 \mathrm{mg} / \mathrm{kg}$ ) (onesided $P$ values 0.015 and 0.02 respectively). However, statistical adjustment for age, sex and baseline APRI revealed that only treatment in group 2 is independently accompanied with $83 \%$ decrease in the risk of DOX-related liver fibrosis. The implication of these circulating factors to predict liver fibrosis is becoming more popular because they are available in many laboratories, they are almost non expensive, and can be repeated several times. Moreover, they may be representative of the fibrosis in the whole liver, thus avoiding small sampling error which is a technical defect in percutaneous liver biopsy [21].

The predictive value of indirect serum markers of liver fibrosis was previously mentioned in conditions such as viral hepatitis and fatty liver disease [1,22]. Unalp-Ardia similarly reported that APRI can be used to predict liver fibrosis with higher scores indicative of advanced liver disease [23]. Moreover, it has been claimed that the combination of APRI with FibroMeter may show an accurate lower cost alternative to liver biopsy to evaluate fibrosis [24]. A meta- analysis showed that APRI $>1$ had a sensitivity of $76 \%$ and a specificity of $72 \%$ to predict cirrhosis in patients infected with hepatitis $\mathrm{C}$ virus (HCV). For significant fibrosis, an APRI threshold of 0.7 was $77 \%$ sensitive and $72 \%$ specific. They concluded that APRI may obviate the need for staging liver biopsy in a subset of patients with HCV infection [14].

Moreover, FIB-4 index as another non-invasive serum marker to delineate liver fibrosis has been implicated in a variety of illnesses including hepatitis B virus (HBV) infection. Mallet investigated the accuracy of FIB-4 index in a group of chronic HBV-infected patients and concluded that a cut-off value $\leq$ 1.45 can differentiate moderate fibrosis from severe fibrosis with a negative predictive value of $86 \%$, a sensitivity of $71.1 \%$ and a specificity of $73.1 \%$. He asserted that it is even more precise than APRI to exclude significant fibrosis [1]. Shah et al. reported that in patients with NAFLD, the FIB-4 index is superior to other non-invasive markers of fibrosis [22]. In addition, a systematic review and meta-analysis showed APRI and FIB-4 can identify hepatitis B-related fibrosis with a moderate sensitivity and accuracy. They 
suggested that an APRI threshold of 0.5 and 1.5 and an FIB4 threshold of 1.45 and 3.25 had acceptable sensitivity and specificity to delineate mild from significant fibrosis [17]. Though we showed that treatment with higher dose DOX (50 mg/ $\mathrm{kg}$ ) may be associated with significant decrease in FIB-4 score (Table 3), we were not able to show its independent association with FIB-4 score.

We also checked FibroTest which is a commercially available algorithm combining different elements, and has been proved to have high predictive value in advanced fibrosis. A cut-off value of 0.58 has been reported to associate with severe fibrosis $(F \geq 3)[19,25]$. Only one patient who was treated with highdose DFO (group 3) exceeded this cut-off point, and the results were comparable in the 3 groups.

The same finding was confirmed with TE that none of our patients experienced significant fibrosis following DOX treatment. They all had a METAVIR score in the F0-F1 zones, compatible with no or mild fibrosis. Meanwhile, we could show that DFO even further decreased serum markers of hepatic fibrosis when administered at a dose of 10 times DOX dose. It may be promising that DFO may play a role in decreasing the chance of liver fibrosis in the long-term. Despite normal LFT, METAVIR score, APRI, FIB-4 index, and FibroTest, nobody can guarantee that these patients are protected from liver fibrosis and cirrhosis when they reach their adulthood. Therefore, there is always a concern that survivors of pediatric malignancy may suffer from multi-organ damage in the future particularly if they are treated with toxic agents such as anthracyclines with proven cardiac and possibly hepatic and renal complications. It is also important to consider that non-invasive predictors of liver fibrosis such as serum markers and FibroScan are more reliable for detection of advanced fibrosis, and are less sensitive in the early stages of liver fibrosis $(F \leq 2)$ [21]. Although none of our patients suffered from severe fibrosis as a result of chemotherapy effect, it is highly recommended to follow these children for at least a decade to investigate the long-term toxicity of chemotherapy agents on the liver and other organs.

Our study had some strengths and limitations. Regarding the strengths, it was the first randomized clinical trial in patients with cancer and especially in the pediatric age group which assessed the role of DFO as a rescue therapy to prevent liver damage induced by DOX. Up to now, only limited animal studies were conducted and this issue makes out our study as the first study of its own. Secondly, we tried to assess liver fibrosis with different modalities including FibroScan, LFT and non-invasive markers of liver fibrosis such as FibroTest, APRI and FIB-4 index. This probably helped us to increase the accuracy of our assessment.

On the other hand, the study faced some limitations. First of all, the small number of our cases and the short period of follow up hinder the generalizability of the results. A larger multi-center study with longer follow up is required to assess the reproducibility of our results. Secondly, the heterogeneity of the study population in terms of their primary diagnosis is another issue that may have confounded the results as the chemotherapy protocols were not the same in all participants. Therefore, the interaction of other chemotherapy agents with DOX and their hepatic side effects cannot be overlooked. Lastly, we didn't have tissue biopsy to assess liver fibrosis in our patients because of ethical issues and the potential hazards of liver biopsy in cancer patients. Though FibroScan, and non-invasive serum markers of fibrosis 
are good alternative to liver biopsy, they are more informative in advanced fibrosis rather than early stages of liver fibrosis [26].

At the end, considering all these pros and cons of the study, our results may shed light for future researches to solve the dark sides of this puzzle. It is highly advised to run a large multi-center trial in a cohort of patients with similar malignancy such as leukemia to know whether DFO may prove beneficial in long-term protection of liver injury related to anthracyclines.

\section{Conclusion}

DOX did not lead to severe fibrosis in the liver provided that not exceeding the maximum allowed cumulative dose. DFO at the dose of 10 times of DOX dose may have a potential protective role against liver fibrosis. Larger multi-center studies are warranted to further assess this hypothesis.

\section{Abbreviations}

Doxorubicin (DOX)

Deferoxamine (DFO)

Liver function tests (LFT)

Hepatitis C virus (HCV)

Y-glutamyltransferase $(\gamma \mathrm{GT})$

a 2 -macroglobulin (a2 MG)

Apo lipoprotein A1 (apoA1)

\section{Declarations}

\section{Ethics approval and consent to participate}

Written informed consent was obtained from all participants or their parents. The Ethics Committee of Shiraz University of Medical Sciences approved the study with the Ethical code IR.SUMS.REC.1394.193. The trial was registered in the Iranian Registry of Clinical Trials with registration No. IRCT2016080315666N4.

\section{Consent for publication}

Not applicable.

\section{Availability of data and materials}


The data that support the findings of this study are available from Research Center of Shiraz University of Medical Science but restrictions apply to the availability of these data, which were used under license for the current study, and so are not publicly available. Data are however available from the authors upon reasonable request and with permission of Research Center of Shiraz University of Medical Science

\section{Competing interests}

All authors declare that they have no conflict of interest.

\section{Funding}

Not applicable.

\section{Authors' contributions}

Study conception and design were done by MB, NS, MF

$\mathrm{SH}, \mathrm{NS}, \mathrm{MS}$ and analyzed and interpreted the data.

Acquisition of data was done by MF, HMV, MB, NS and GF

GF, MB and MD drafted the manuscript.

The critical revision was done by all authors.

All authors reviewed and approved the final manuscript.

\section{Acknowledgment}

This study was conducted as part of the fellowship training of G. Fathpour as a pediatric hematologist, and was funded by Shiraz University of Medical Sciences with grant number 93-01-01-8638. We greatly appreciate the Clinical Research Development center and Ms. Neda Sadat Boyer for editorial assistant.

\section{References}

1. Mallet V, Dhalluin-Venier V, Roussin C, Bourliere M, Pettinelli M, Giry C, Vallet-Pichard A, Fontaine H, Pol S: The accuracy of the FIB-4 index for the diagnosis of mild fibrosis in chronic hepatitis B. Aliment Pharmacol Ther 2009, 29(4):409-415.

2. McGowan JV, Chung R, Maulik A, Piotrowska I, Walker JM, Yellon DM: Anthracycline chemotherapy and cardiotoxicity. Cardiovasc Drugs Ther 2017, 31(1):63-75.

3. Hoekman K, van der Vijgh WJ, Vermorken JB: Clinical and preclinical modulation of chemotherapyinduced toxicity in patients with cancer. Drugs 1999, 57(2):133-155.

4. King PD, Perry MC: Hepatotoxicity of chemotherapy. The oncologist 2001, 6(2):162-176. 
5. Zafrani ES, Leclercq B, Vernant JP, Pinaudeau Y, Chomette G, Dhumeaux D: Massive blastic infiltration of the liver: a cause of fulminant hepatic failure. Hepatology 1983, 3(3):428-432.

6. Liu L-L, Li Q-X, Xia L, Li J, Shao L: Differential effects of dihydropyridine calcium antagonists on doxorubicin-induced nephrotoxicity in rats. Toxicology 2007, 231(1):81-90.

7. Ghibu S, Delemasure S, Richard C, Guilland J-C, Martin L, Gambert S, Rochette L, Vergely C: General oxidative stress during doxorubicin-induced cardiotoxicity in rats: absence of cardioprotection and low antioxidant efficiency of alpha-lipoic acid. Biochimie 2012, 94(4):932-939.

8. Mizutani H, Tada-Oikawa S, Hiraku Y, Kojima M, Kawanishi S: Mechanism of apoptosis induced by doxorubicin through the generation of hydrogen peroxide. Life Sci 2005, 76(13):1439-1453.

9. Carvalho C, Santos RX, Cardoso S, Correia S, Oliveira PJ, Santos MS, Moreira PI: Doxorubicin: the good, the bad and the ugly effect. Curr Med Chem 2009, 16(25):3267-3285.

10. Lee H-J, Lee J, Lee S-K, Lee S-K, Kim E-C: Differential regulation of iron chelator-induced IL-8 synthesis via MAP kinase and NF-KB in immortalized and malignant oral keratinocytes. BMC cancer 2007, 7(1):176.

11. Leman Yalcintepe EH: Modulation of iron metabolism by iron chelation regulates intracellular calcium and increases sensitivity to doxorubicin. Bosn J Basic Med Sci 2016, 16(1):14.

12. Yamasaki T, Terai S, Sakaida I: Deferoxamine for advanced hepatocellular carcinoma. N Engl J Med 2011, 365(6):576-578.

13. Al-Bekairi AM, Osman AMM, Hafeez MA, Al-Gharably NM, Al-Shabanah OA, Al-Harbi MM: Effect of desferrioxamine on the hepatotoxicity of adriamycin in normal mice. Drug development research 1993, 29(1):56-62.

14. Lin ZH, Xin YN, Dong QJ, Wang Q, Jiang XJ, Zhan SH, Sun Y, Xuan SY: Performance of the aspartate aminotransferase-to-platelet ratio index for the staging of hepatitis C-related fibrosis: an updated meta-analysis. Hepatology 2011, 53(3):726-736.

15. Reddy SK, Reilly C, Zhan M, Mindikoglu AL, Jiang Y, Lane BF, Alexander HR, Culpepper WJ, El-Kamary SS: Long-term influence of chemotherapy on steatosis-associated advanced hepatic fibrosis. Medical oncology (Northwood, London, England) 2014, 31(6):971.

16. Vallet-Pichard A, Mallet V, Nalpas B, Verkarre V, Nalpas A, Dhalluin-Venier V, Fontaine H, Pol S: FIB-4: an inexpensive and accurate marker of fibrosis in $\mathrm{HCV}$ infection. comparison with liver biopsy and fibrotest. Hepatology 2007, 46(1):32-36.

17. Xiao G, Yang J, Yan L: Comparison of diagnostic accuracy of aspartate aminotransferase to platelet ratio index and fibrosis-4 index for detecting liver fibrosis in adult patients with chronic hepatitis $B$ virus infection: a systemic review and meta-analysis. Hepatology 2015, 61(1):292-302.

18. Hudson M, Sheron N, Rowe IA, Hirschfield GM: Should we screen for cirrhosis? BMJ 2017:j3233.

19. Thiele M, Madsen BS, Hansen JF, Detlefsen S, Antonsen S, Krag A: Accuracy of the Enhanced Liver Fibrosis Test vs FibroTest, Elastography, and Indirect Markers in Detection of Advanced Fibrosis in Patients With Alcoholic Liver Disease. Gastroenterology 2018, 154(5):1369-1379. 
20. Saad SY, Najjar TA, Al-Rikabi AC: The preventive role of deferoxamine against acute doxorubicininduced cardiac, renal and hepatic toxicity in rats. Pharmacol Res 2001, 43(3):211-218.

21. Lambrecht J, Verhulst S, Mannaerts I, Reynaert $H$, van Grunsven LA: Prospects in non-invasive assessment of liver fibrosis: Liquid biopsy as the future gold standard? Biochim Biophys Acta 2018.

22. Shah AG, Lydecker A, Murray K, Tetri BN, Contos MJ, Sanyal AJ, Network NCR: Comparison of noninvasive markers of fibrosis in patients with nonalcoholic fatty liver disease. Clin Gastroenterol Hepatol 2009, 7(10):1104-1112.

23. Unalp-Arida A, Ruhl CE: Liver fibrosis scores predict liver disease mortality in the United States population. Hepatology 2017, 66(1):84-95.

24. Chindamo MC, Boursier J, Luiz RR, Fouchard-Hubert I, Pannain VLN, de Araújo Neto JM, Coelho HSM, de Mello Perez R, Calès P, Villela-Nogueira CA: Fibrosis assessment using FibroMeter combined to first generation tests in hepatitis C. World journal of hepatology 2017, 9(6):310.

25. Imbert-Bismut F, Ratziu V, Pieroni L, Charlotte F, Benhamou Y, Poynard T: Biochemical markers of liver fibrosis in patients with hepatitis $C$ virus infection: a prospective study. The Lancet 2001, 357(9262):1069-1075.

26. Lurie $Y$, Webb M, Cytter-Kuint R, Shteingart S, Lederkremer GZ: Non-invasive diagnosis of liver fibrosis and cirrhosis. World journal of gastroenterology 2015, 21(41):11567-11583.

\section{Figures}




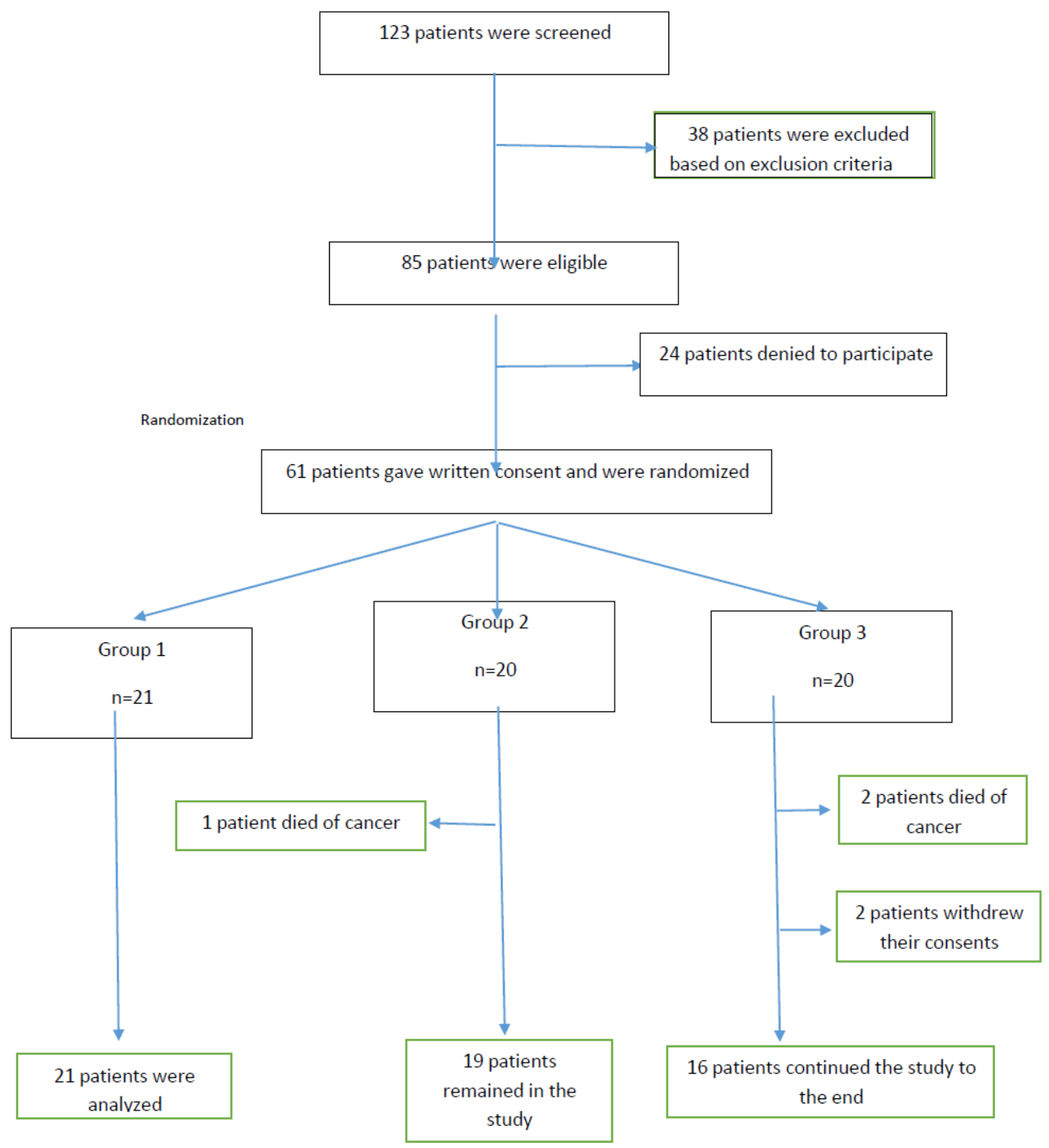

\section{Figure 1}

Flowchart of the study population screening and their randomization 


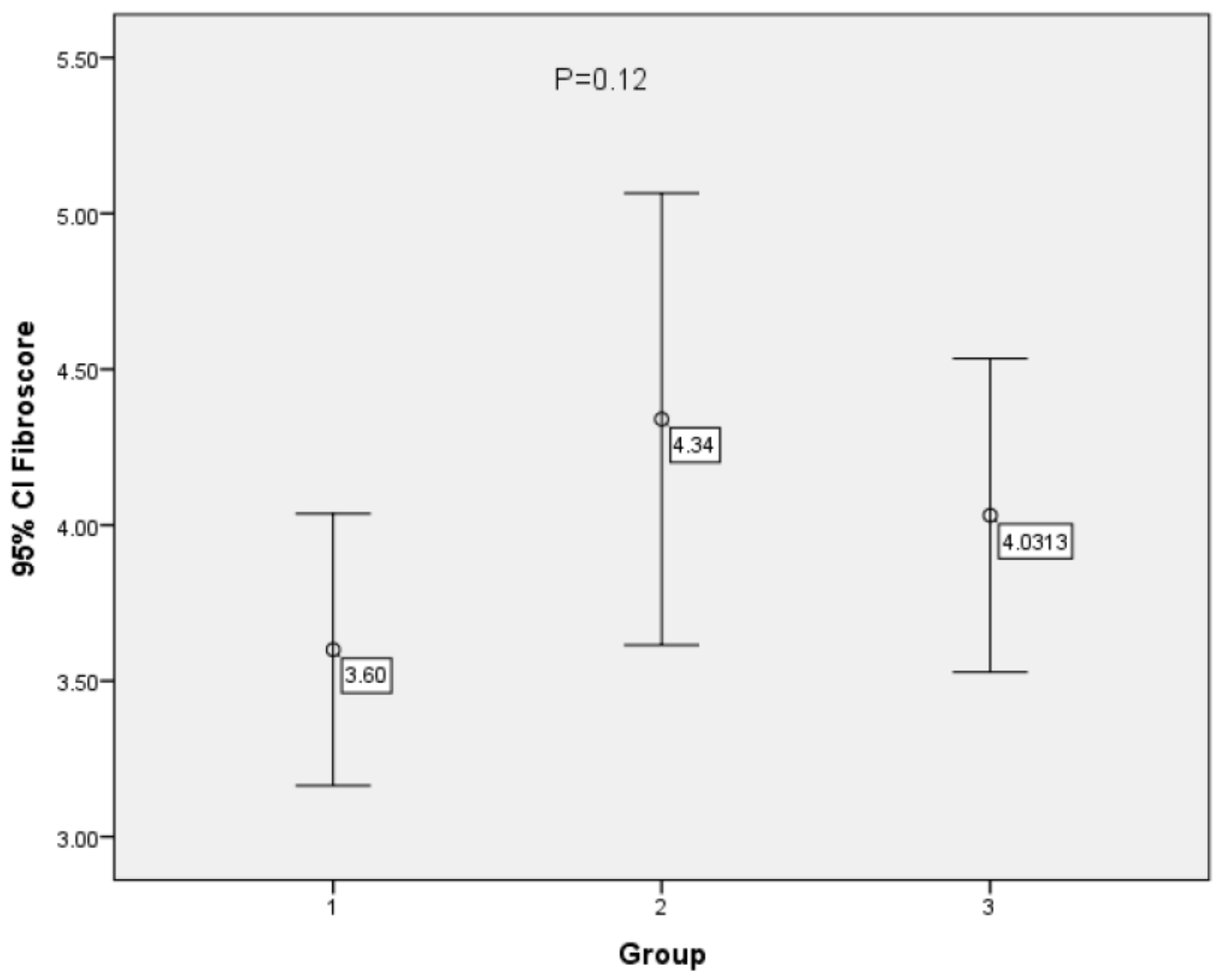

Figure 2

Assessment of liver stiffness by FibroScan in the 3 groups post-Deferoxamine treatment

\section{Supplementary Files}

This is a list of supplementary files associated with this preprint. Click to download.

- SupplementTable1.docx

- CONSORTfile.doc 